\title{
Nitrogen fluorescence induced by the femtosecond intense laser pulses in air
}

\author{
$\mathrm{He} \mathrm{Li}^{1,2}$, Suyu $\mathrm{Li}^{1,2}$, Shuchang $\mathrm{Li}^{1,2}$, Dunli $\mathrm{Liu}^{1,2}$, Dan $\mathrm{Tian}^{1,2}$, Anmin $\mathrm{Chen}^{1,2}$, Ying Wang ${ }^{1,2}$, \\ Xiaowei Wang ${ }^{1,2}$, Yunfeng Zhang ${ }^{1,2}$, and Mingxing Jin $^{1,2}$ \\ ${ }^{1}$ Institute of Atomic and Molecular Physics, Jilin University, Changchun 130012, China \\ ${ }^{2}$ Jilin Provincial Key Laboratory of Applied Atomic and Molecular Spectroscopy (Jilin University), Changchun 130012, China \\ (Received 4 September 2015; revised 18 January 2016; accepted 4 February 2016)
}

\begin{abstract}
Our experiments show that external focusing and initial laser energy strongly influences filament generated by the femtosecond Ti-sapphire laser in air. The experimental measurements show the filament length can be extended both by increasing the laser energy and focal length of focusing lens. On the other hand, the plasma fluorescence emission can be enhanced by increasing the laser energy with fixed focal length or decreasing the focal length. In addition, the collapse distance measured experimentally are larger than the calculated ones owing to the group-velocity-dispersion effect. In addition, we find that the line widths of the spectral lines from $\mathrm{N}_{2}$ is independent of filament positions, laser energies and external focusing.
\end{abstract}

Keywords: femtosecond laser; filament; fluorescence

\section{Introduction}

A stable plasma channel will be formed when the Kerr self-focusing and plasma defocusing resulted from the multiphoton ionization reach a dynamical balance, which is called filament. Since the laser beam can propagate a few kilometres or tens of kilometres ${ }^{[1]}$, filaments itself and the appearance of nonlinear effects, such as supercontinuum spectrum generation ${ }^{[2,3]}$, terahertz radiation ${ }^{[4,5]}$, highorder harmonic generation ${ }^{[6,7]}$, have important value both in the study of basic physics and in practical applications such as the $\operatorname{LIDAR}^{[8]}$, remote sensing ${ }^{[9-11]}$, laser triggered lightning ${ }^{[12,13]}$, rain and snow precipitation ${ }^{[13,14]}$ and so on.

The plasma generation balances the Kerr self-focusing effect and leads to a limited beam diameter as well as limited peak intensity around $5 \times 10^{13} \mathrm{~W} / \mathrm{cm}^{2}$ (Refs. $\left.[15,16]\right)$, which is known as intensity clamping. The intensity of filament is high enough to stimulate and ionize air molecule thus emitting the characteristic spectral line of atoms and molecules, which has found applications in sensing atmospheric trace species $^{[9-11]}$. In previous works, experimental research in the field of filamentation created filaments typically a few metres in the laboratory ${ }^{[17-19]}$ and over hundreds of metres

Correspondence to: S. Li and M. Jin, Institute of Atomic and Molecular Physics, Jilin University, Changchun, Jilin Province 130012, China. Email: suyu11@mails.jlu.edu.cn, mxjin@jlu.edu.cn at a range of few kilometres in the atmosphere ${ }^{[20-22]}$, making the remote sensing possible. Since the intensity of plasma fluorescence is related to that of the laser beam, plasma fluorescence spectra along the propagation path can be used to characterize the femtosecond filamentation process. More importantly, the filament-induced fluorescence technique can be used to identify different substances at different positions, even remotely, which can also open perspectives for transmitting optical data in ambient air.

In this work, the plasma fluorescence generated by femtosecond laser pulses is measured along the propagation path to investigate the femtosecond filamentation process. The influence of pulse energy and focal length of the external lens on plasma fluorescence emission as well as filamentation process in air is studied.

\section{Experiment setup}

Experiments are carried out using a Ti:sapphire laser system, which generates femtosecond laser pulses with a central wavelength of $800 \mathrm{~nm}$, a repetition rate of $1 \mathrm{kHz}$ and a pulse duration of $50 \mathrm{fs}$ at full width at half maximum (FWHM). The input diameter $\left(1 / e^{2}\right)$ of laser beam is $5 \pm 0.1 \mathrm{~mm}$. The experiment setup is shown in Figure 1. The combination of a half-wave plate and a Glan laser polarizer attenuates laser energy to the desired value. The lenses $L$ with focal length 


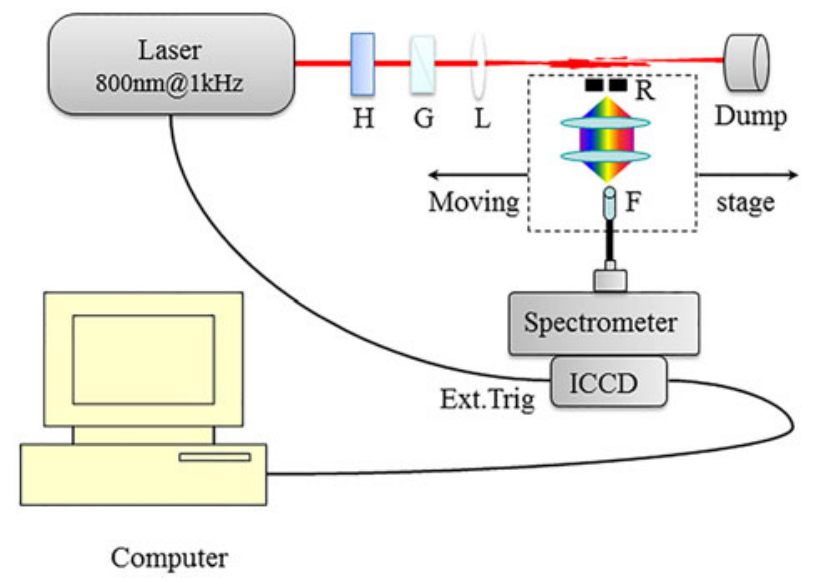

Figure 1. Schematic of experimental setup to measure the plasma fluorescence generated during the femtosecond filamentation in air. G: Glan prism; H: half-wave plate; L: focusing lens; R: rectangular diaphragm; F: optical fibre.

of 40 and $100 \mathrm{~cm}$ are used to achieve the focal geometries (numerical aperture $(\mathrm{NA}))$ of $f / 40(\mathrm{NA}=0.00625)$ and $f / 100(\mathrm{NA}=0.0025)$. The filament-induced fluorescence is collected by lenses (fused silica $f=50 \mathrm{~mm}$ ) and the spectra are guided to the spectrometer (Spectra Pro 500i, PI Acton, and the grating is 2400 and 150 grooves $/ \mathrm{mm}$ ) through an optical fibre fixed on the moving stage. The fluorescence is detected using an intensified charge coupled device (ICCD, PI-MAX, Princeton Instruments) with $1024 \times 1024$ pixels. A rectangular diaphragm $(1 \mathrm{~mm} \times 10 \mathrm{~mm})$ is placed $10 \mathrm{~mm}$ away from the filament axis to resolve longitudinally the fluorescence signal along the propagation path. Each data point throughout this paper is typically an average of 20 groups of 500 shots' accumulation so as to reduce the error and thus improve the signal-to-noise ratio.

\section{Results and discussion}

It should be noted that in the experiments, the nearest distance between the focusing lens $L$ and the optical fibre probe fixed on the moving stage is $d=36$ and $82.5 \mathrm{~cm}$ as the focal length is 40 and $100 \mathrm{~cm}$, respectively. For convenience, we define these positions as $z=0 \mathrm{~mm}$; thus, the actual propagation distance is $Z=z+d$. Figure 2(a) shows the variation of plasma fluorescence spectra with $z$ as the focal length is $f=100 \mathrm{~cm}$ and the laser energy is $2.2 \mathrm{~mJ}$. It is found that along with the increase of $z$, the intensity of fluorescence increases firstly and then decreases after reaching its maximum value around $80 \mathrm{~mm}$. In order to show the process more clearly, we select the spectral line around $337 \mathrm{~nm}$ at 68, 78, and $94 \mathrm{~mm}$, as shown in Figure 2(b). The variation of fluorescence spectra is in agreement with that of plasma density and light intensity obtained in previous theoretical and experimental work. Besides, it can be seen from Figure 3 that all the spectral lines show the similar variation tendency along the propagation direction, which further illustrates that one of the spectral lines can be used to characterize the femtosecond filamentation process. In the following part, we utilize the $337 \mathrm{~nm}$ signal to study plasma fluorescence emission during filamentation in air.

Figure 4(a) shows the variation of spectrum intensity around $337 \mathrm{~nm}$ signal $(332-341 \mathrm{~nm})$ with $z$. It can be clearly seen from the figure that with the increase of the initial energy of the laser pulse $E_{\text {in }}$, the onset of filaments moves towards the focus of the lens and the fluorescence intensity increases significantly. In addition, the filament length also
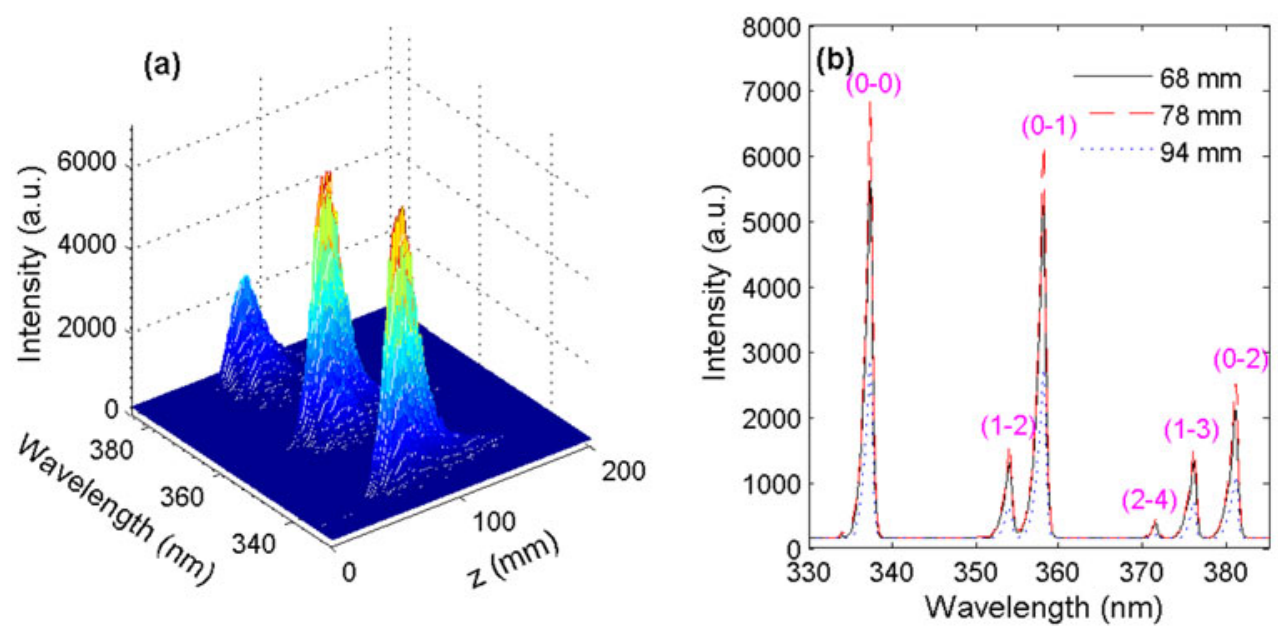

Figure 2. (a) Change of fluorescence spectra with the propagation distance $z$. (b) Fluorescence spectra measured as $z$ is $68 \mathrm{~mm}$ (solid black line), $78 \mathrm{~mm}$ (dash-dotted red line), and $94 \mathrm{~mm}$ (dotted blue line). The focal length is $100 \mathrm{~cm}$ and laser energy is $2.2 \mathrm{~mJ}$. The pink words marked above the lines correspond to the signals from the second positive band system of $\mathrm{N}_{2}\left(C^{3} \Pi_{u}-B^{3} \Pi_{g} \text { transition }\right)^{[23-26]}$. In the transitions $v-v^{\prime}, v$ and $v^{\prime}$ denote the vibrational levels of upper and lower electronic states, respectively. 


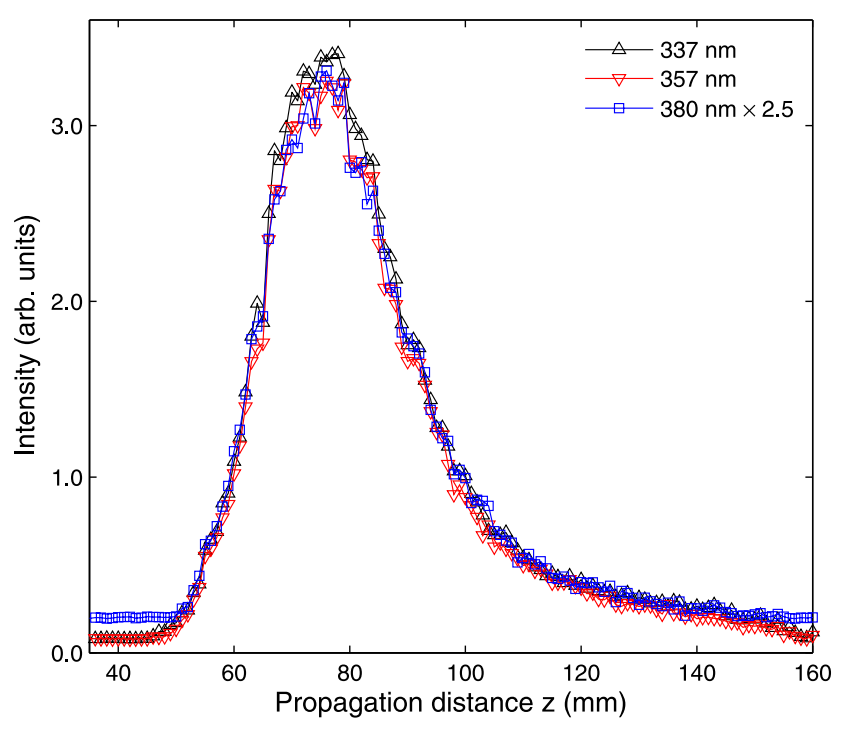

Figure 3. Change of 337, 357, and $380 \mathrm{~nm}$ spectral lines with $z$. The focal length is $100 \mathrm{~cm}$ and laser energy is $2.2 \mathrm{~mJ}$.

increases with increasing $E_{\text {in }}$. To investigate the process more clearly, we present the variation of the intensity of $337 \mathrm{~nm}$ spectral line with the propagation distance $z$, as shown in Figures 4(b) and (c). We can clearly see from the figure that with the increase of laser energy, the position corresponding to the strongest spectral line (here, we call it collapse distance $L_{\mathrm{c}}$ ) decreases from 125 to $57 \mathrm{~mm}$. For this phenomenon, we can explain it by the semi-empirical selffocusing formula.

For the Gaussian pulse adopted in our experiment, its collapse distance $L_{\mathrm{c}}$ can be well estimated by the semiempirical self-focusing formula ${ }^{[27,28]}$ :

$$
L_{\mathrm{c}}=\frac{0.367 k_{0} w_{0}^{2}}{\sqrt{\left[\left(P_{\mathrm{in}} / P_{\mathrm{c}}\right)^{1 / 2}-0.0852\right]^{2}-0.0219}},
$$

where $P_{\text {in }}=E_{\text {in }} /(\tau \sqrt{\pi / 2})$ is initial laser power, and $P_{\mathrm{c}}=3.77 \lambda_{0}^{2} / 8 \pi n_{0} n_{2}=3.2 \mathrm{GW}$ is critical power for self-focusing. Since the focusing lenses are used in our experiment, the position where the pulse collapse occurs (corresponding to the highest fluorescence intensity) moves towards the linear focus of the focusing lens:

$$
\frac{1}{L_{\mathrm{c}}^{\prime}}=\frac{1}{L_{\mathrm{c}}}+\frac{1}{f}
$$

where $f$ denotes the focal length of the lens. Figure 5(a) presents the collapse distance obtained from experimental measurement (red circles) and that calculated from Equation (2) (blue squares) when the focal length is $100 \mathrm{~cm}$. It can be seen from the figure that the experimental results are in good agreement with the calculated ones; however, the latter
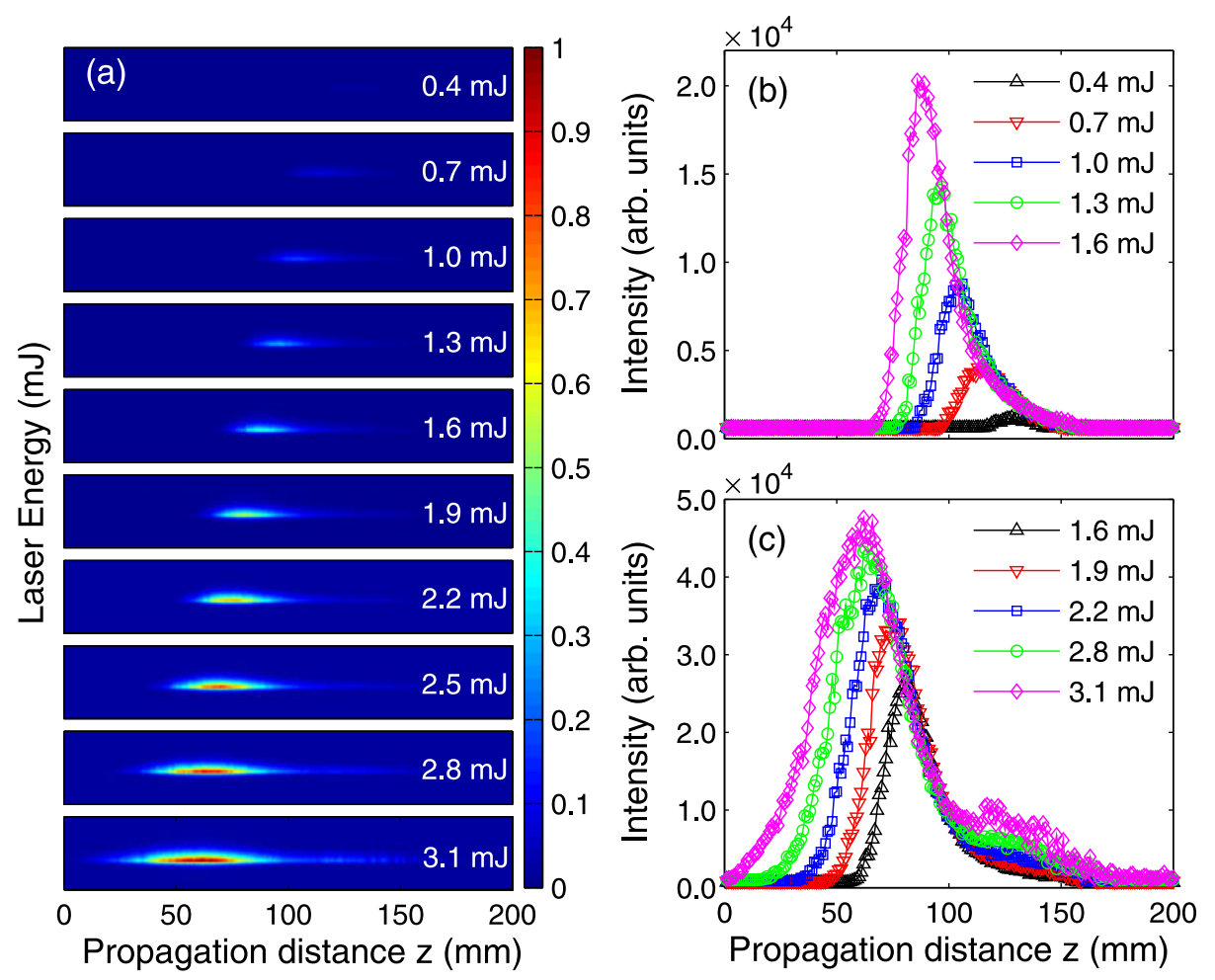

Figure 4. (a) Variation of the spectrum intensity around $337 \mathrm{~nm}(332-341 \mathrm{~nm})$ with $z$ as the pulse energy is different; (b) and (c) variation of the maximum intensity of spectral line at $337 \mathrm{~nm}$ with $z$. The focal length is $f=100 \mathrm{~cm}$. 


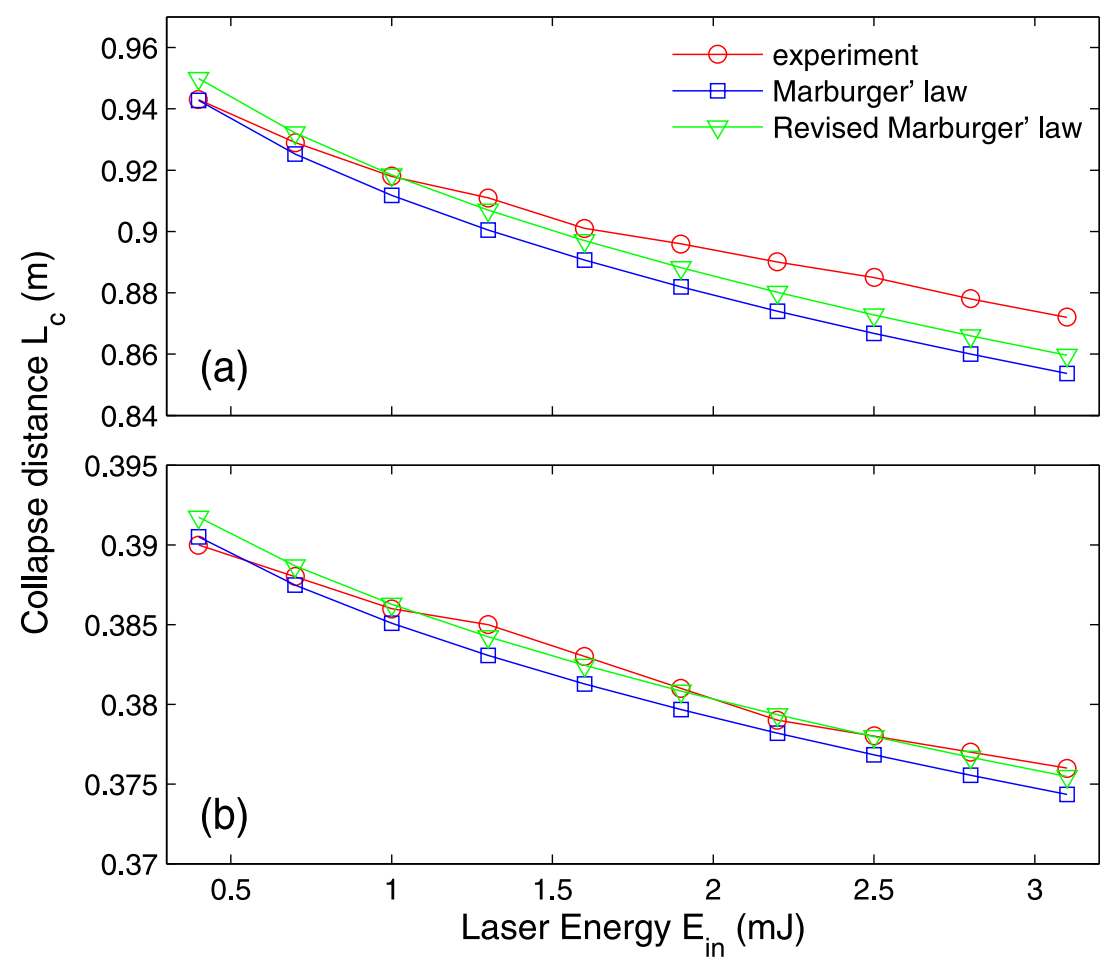

Figure 5. Variation of collapse distance when focal length is (a) 100 and (b) $40 \mathrm{~cm}$. The red circles are the experimental values, and the blue squares and green triangles refer to the collapse distance calculated from Marburger's law (Equation (2)) and revised Marburger's law (Equation (3)).

is slightly larger than the former, which can be attributed to the fact that the group-velocity-dispersion (GVD) effect plays the defocusing role ${ }^{[29]}$. It is believed that the difference will become more evident as the pulse duration is shorter. By introducing the GVD length $L_{\mathrm{GVD}}=\tau_{0}^{2} / k^{\prime \prime}\left(k^{\prime \prime}=2 \times\right.$ $10^{-29} \mathrm{~s}^{2} / \mathrm{m}$ refers to the second order dispersion coefficient) into the semi-empirical Marburger's law, Li and Jin proposed a revised Marburger's law ${ }^{[30]}$ :

$$
\frac{1}{L_{\mathrm{c}}^{\prime}}=\frac{1}{L_{\mathrm{c}}}+\frac{1}{f}-\frac{1}{L_{\mathrm{GVD}}} .
$$

By using the revised Marburger's law, the collapse distance becomes much closer to the experimental results, as shown by the green triangles in Figure 5(a).

Jim et al. divide the filamentation into linear-focusing (high-NA) and nonlinear-focusing (low-NA) ${ }^{[31]}$ regime according to the NA size. In the following, by using the lens of $f=40 \mathrm{~cm}$, we investigate the variation of fluorescence intensity around $337 \mathrm{~nm}$ in the linear-focusing (high-NA) case, as shown in Figure 6(a). The spectrum intensity is stronger than that in the longer focal length case because the plasma density increases when the focal length decreases ${ }^{[32]}$. The filament length is about 4 times shorter than that in the longer focal length case and the collapse distance does not change much. In order to describe the process more clearly, the variation of the intensity of $337 \mathrm{~nm}$ spectral line with the propagation distance $z$ is presented in Figures 6(b) and (c).
Within the present energy range $(0.4-3.1 \mathrm{~mJ})$, the filament length increases with increasing laser energy, indicating that the filament length can be effectively prolonged by increasing the laser energy. On the other hand, with the increase of laser energy, the fluorescence intensity increases gradually and the position of pulse collapse moves towards the focus of the lens. As is shown in Figure 5(b), the collapse distance calculated from Equation (2) is in good agreement with the experimental value. However, the latter is still slightly larger than the former due to the GVD effect. On the other hand, $L_{c}$ calculated from Equation (3) (green triangles) and that obtained from the experimental measurement (red circles) are almost consistent with each other.

As is shown in Figures 4(a) and 6(a), when the pulse energy is $0.4 \mathrm{~mJ}$, the incident pulse power is $P_{\text {in }}=6.4 \mathrm{GW}=$ $2 P_{\mathrm{c}}$. That is to say, though the fluorescence intensity is low, it does not mean that there is no filament. Since the laser intensity is clamped around $5 \times 10^{13} \mathrm{~W} / \mathrm{cm}^{2}$ in the filamentation process and the diameter of the core of filaments is about $100 \mu \mathrm{m}$, consequently, along with increasing laser energy, the initial power will be much larger than the critical power for self-focusing eventually. In this case, the filament will split into multi-filament, thereby enlarging the filament volume. As a result, more excited nitrogen molecules will be contained within these filaments, thus generating stronger $337 \mathrm{~nm}$ signal. In fact, in the case of shorter focal length, the plasma density increases greatly ${ }^{[32]}$. By comparing the filaments generated in the 


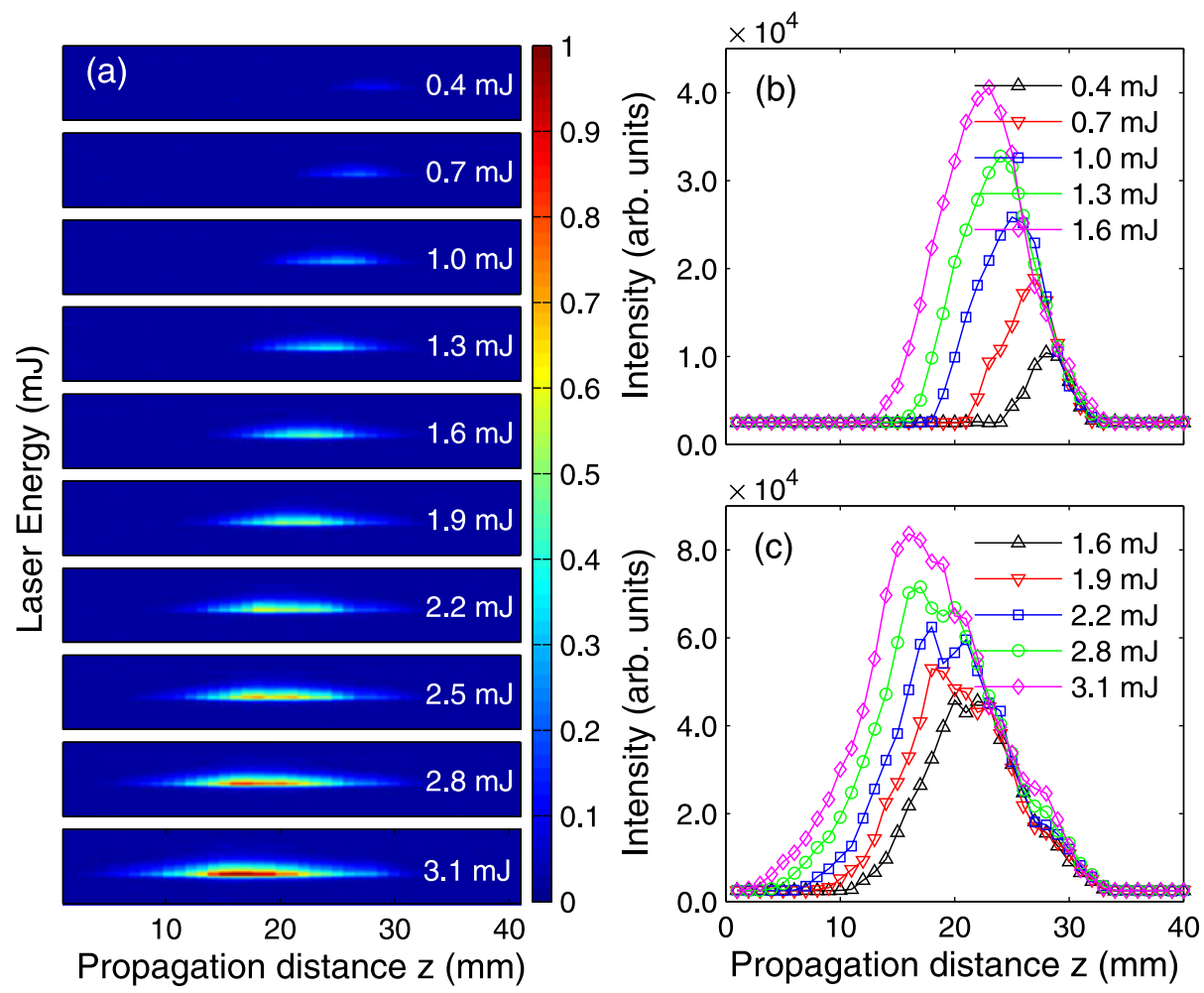

Figure 6. (a) Variation of the spectrum intensity around $337 \mathrm{~nm}$ signal (332-341 nm) with $z$; (b) and (c) z-evolution of the $337 \mathrm{~nm}$ signal. The focal length is $40 \mathrm{~cm}$ and the laser energy is changed from 0.4 to $3.1 \mathrm{~mJ}$.

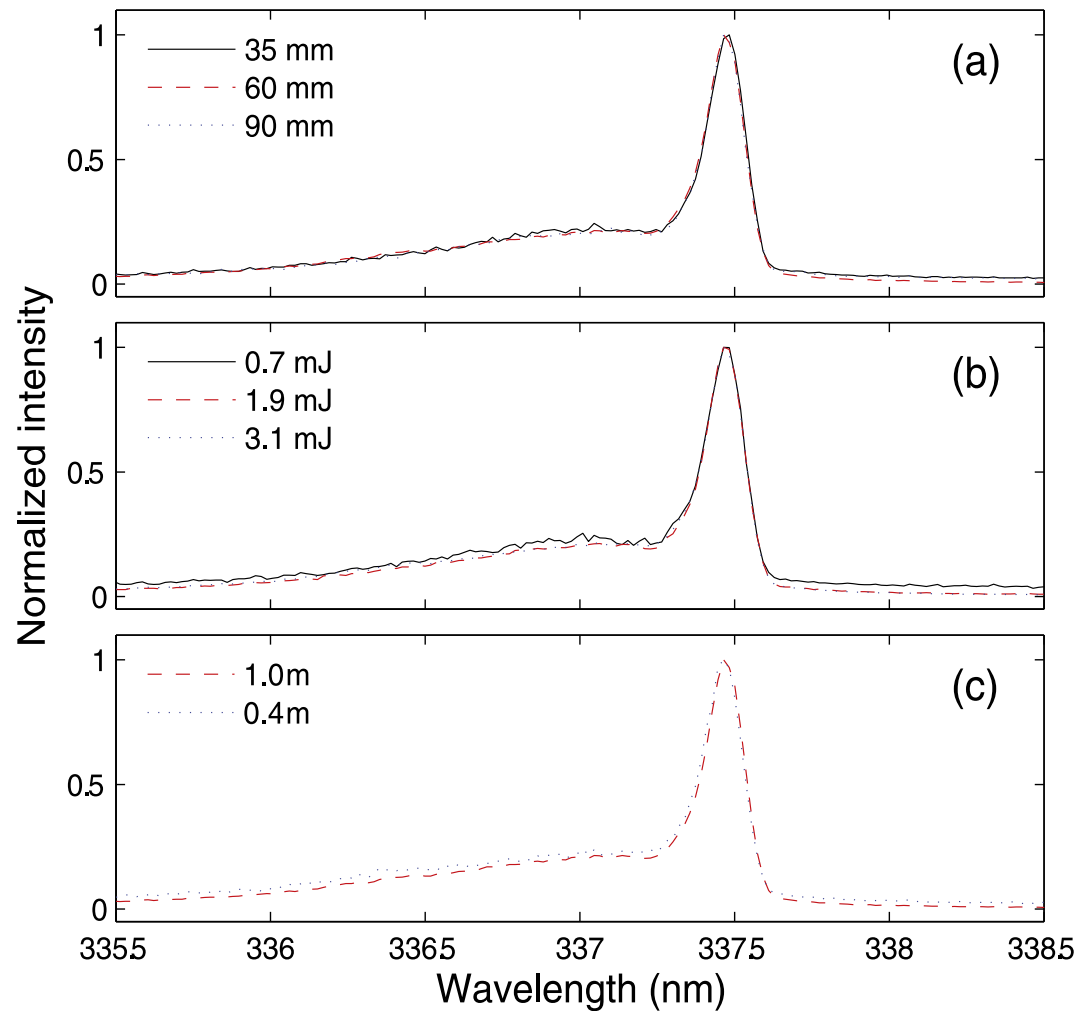

Figure 7. Normalized spectrum intensity (a) at 35,60 , and $90 \mathrm{~mm}$ as the focal length $f$ is $100 \mathrm{~cm}$ and laser energy $E_{\text {in }}$ is $3.1 \mathrm{~mJ}$; (b) as $f$ is $100 \mathrm{~cm}$ and $E_{\text {in }}$ is $0.7 \mathrm{~mJ}(z=114 \mathrm{~mm}), 1.9 \mathrm{~mJ}(z=75 \mathrm{~mm})$, and $3.1 \mathrm{~mJ}(z=60 \mathrm{~mm})$; (c) as $E_{\text {in }}$ is $3.1 \mathrm{~mJ}$ and the focal length is $100(z=60 \mathrm{~mm})$ and $40 \mathrm{~cm}(z=16 \mathrm{~mm})$. 
linear $\left(\mathrm{NA}=6.25 \times 10^{-3}\right)$ and nonlinear $\left(\mathrm{NA}=2.5 \times 10^{-3}\right)$ focusing cases, it is found that in the linear (NA $=6.25 \times$ $10^{-3}$ ) focusing case, the filament length is reduced and the fluorescence intensity is enhanced.

Figure 7 shows the normalized spectra around $337 \mathrm{~nm}$ at different positions, laser energies and NAs. It can be seen clearly from Figure 7 that these factors do not affect the width of the spectral line, which is different from those from atomic ions and atoms. In effect, the same phenomena can be observed for $357 \mathrm{~nm}, 380 \mathrm{~nm}$, and other spectral lines that comes from $\mathrm{N}_{2}$ and $\mathrm{N}_{2}^{+}$. For this phenomenon, we can attribute it to the fact that for diatomic molecules, the energy difference between different vibrational-rotational state are constant, independent of internuclear distance $R$ (Ref. [33]), i.e., the vibrational levels of electronic states are relatively stable, respectively.

\section{Conclusion}

In this paper, $337 \mathrm{~nm}$ spectral line is used to represent the filamentation process in the case of external focusing lens with different focal lengths. It is found that the filament length can be effectively extended by increasing the laser energy and focal length of focusing lens. However, there exists something different: the intensity of plasma fluorescence can be enhanced by increasing the laser energy in the case of fixed focal length, while it becomes weaker by increasing the focal length in the case of fixed laser energy. It is also found that the smaller the focal length of the focusing lens, the closer the onset of filamentation is to the geometrical focus of lens, and the collapse distance measured is in agreement with the calculated ones by the semi-empirical Marburger's law. The former is a little larger than the latter, which can be attributed to the GVD effect, and by utilizing the revised Marburger's law, they become much closer to each other. In the end, it is found that the line width of the spectral lines from $\mathrm{N}_{2}$ is independent of filament positions, laser energies and NAs which is different from the spectral lines from ions and atoms.

\section{Acknowledgements}

This work was supported by the National Basic Research Program of China (No. 2013CB922200), the National Natural Science Foundation of China (Nos. 11474129, and 11504129), the Research Fund for the Doctoral Program of Higher Education (No. 20130061110021), and the Graduate Innovation Fund of Jilin University (No. 2015091).

\section{References}

1. L. Wöste, C. Wedekind, H. Rairoux, B. Stein, S. Nikolov, and C. Werner, Laser Optoelektron. 29, 51 (1997).
2. H. Yang, J. Zhang, Q. J. Zhang, Z. Q. Hao, Y. T. Li, Z. Y. Zheng, Z. H. Wang, Q. L. Dong, X. Lu, Z. Y. Wei, Z. M. Sheng, J. Yu, and W. Yu, Opt. Lett. 30, 534 (2005).

3. Y. Petit, S. Henin, W. M. Nakaema, P. Béjot, A. Jochmann, S. D. Kraft, S. Bock, U. Schramm, K. Stelmaszczyk, P. Rohwetter, J. Kasparian, R. Sauerbrey, L. Wöste, and J. P. Wolf, Phys. Rev. A 83, 013805 (2011).

4. C. D. Amico, A. Houard, M. Franco, B. Prade, A. Mysyrowicz, A. Couairon, and V. T. Tikhonchuk, Phys. Rev. Lett. 98, 235002 (2007).

5. H. C. Wu, J. Meyer-ter-Vehn, H. Ruhl, and Z. M. Sheng, Phys. Rev. E 83, 036407 (2011).

6. Y. Tamaki, J. Itatani, Y. Nagata, M. Obara, and K. Midorikawa, Phys. Rev. Lett. 82, 1422 (1999).

7. T. Popmintchev, M. C. Chen, D. Popmintchev, P. Arpin, S. Brown, S. Ališauskas, G. Andriukaitis, T. Balčiunas, O. D. Mücke, A. Pugzlys, A. Baltuška, B. Shim, S. E. Schrauth, A. Gaeta, C. Hernández-García, L. Plaja, A. Becker, A. J. Becker, M. M. Murnane, and H. C. Kapteyn, Science 336, 1287 (2012).

8. J. Kasparian, M. Rodriguez, G. Méjean, J. Yu, E. Salmon, H. Wille, R. Bourayou, S. Frey, Y.-B. André, A. Mysyrowicz, R. Sauerbrey, J.-P. Wolf, and L. Wöste, Science 301, 61 (2003).

9. S. L. Chin, H. L. Xu, Q. Luo, F. Théberge, W. Liu, J. F. Daigle, Y. Kamali, P. T. Simard, J. Bernhardt, S. A. Hosseini, M. Sharifi, G. Méjean, A. Azarm, C. Marceau, O. Kosareva, V. P. Kandidov, N. Aközbek, A. Becker, G. Roy, P. Mathieu, J. R. Simard, M. Châteauneuf, and J. Dubois, Appl. Phys. B 95, 1 (2009)

10. H. L. Xu and S. L. Chin, Sensors 11, 32 (2011).

11. P. Rairoux, H. Schillinger, S. Niedermeier, M. Rodriguez, F. Ronneberger, R. Sauerbrey, B. Stein, D. Waite, C. Wedekind, H. Wille, L. Wöste, and C. Ziener, Appl. Phys. B 71, 573 (2000).

12. X. M. Zhao, J.-C. Diels, C. Y. Wang, and J. M. Elizondo, IEEE J. Quantum Electron. 31, 599 (1995).

13. P. Rohwetter, J. Kasparian, K. Stelmaszczyk, Z. Hao, S. Henin, N. Lascoux, W. M. Nakaema, Y. Petit, M. Queisser, R. Salame, E. Salmon, L. Wöste, and J.-P. Wolf, Nat. Photonics 4, 451 (2010)

14. J. Ju, J. Liu, C. Wang, H. Sun, W. Wang, X. Ge, C. Li, S. L. Chin, R. Li, and Z. Xu, Opt. Lett. 37, 1214 (2012).

15. J. Kasparian, R. Sauerbrey, and S. L. Chin, Appl. Phys. B 71, 877 (2000).

16. W. Liu, S. Petit, A. Becker, N. Aközbek, C. M. Bowden, and S. L. Chin, Opt. Commun. 202, 189 (2002).

17. A. Braun, G. Korn, X. Liu, D. Du, J. Squier, and G. Mourou, Opt. Lett. 20, 73 (1995).

18. A. Zaïr, A. Guandalini, F. Schapper, M. Holler, J. Biegert, L. Gallmann, A. Couairon, M. Franco, A. Mysyrowicz, and U. Keller, Opt. Express 15, 5394 (2007).

19. A. Talebpour, S. Petit, and S. L. Chin, Opt. Commun. 171, 285 (1999).

20. M. Rodriguez, R. Bourayou, G. Méjean, J. Kasparian, J. Yu, E. Salmon, A. Scholz, B. Stecklum, J. Eislöffel, U. Laux, A. P. Hatzes, R. Sauerbrey, L. Wöste, and J.-P. Wolf, Phys. Rev. E 69, 036607 (2004).

21. G. Méchain, C. D. Amico, Y.-B. André, S. Tzortzakis, M. Franco, B. Prade, A. Mysyrowicz, A. Couairon, E. Salmon, and R. Sauerbrey, Opt. Commun. 247, 171 (2005).

22. S. Eisenmann, E. Louzon, Y. Katzir, T. Palchan, A. Zigler, Y. Sivan, and G. Fibich, Opt. Express 15, 2779 (2007).

23. F. R. Gilmore, R. R. Laher, and P. J. Espy, J. Phys. Chern. Ref. Data 21, 1005 (1992). 
24. A. Talebpour, M. Abdel-Fattah, A. D. Bandrauk, and S. L. Chin, Laser Phys. 11, 68 (2001).

25. G. N. Gibson, R. R. Freeman, and T. J. McIlrath, Phys. Rev. Lett. 67, 1230 (1991).

26. S. Y. Li, S. C. Li, L. Z. Sui, Y. F. Jiang, A. M. Chen, and M. X. Jin, Phys. Rev. A 93, 013405 (2016).

27. L. Dawes and J. H. Marburger, Phys. Rev. 179, 862 (1969).

28. H. Marburger, Prog. Quantum Electron. 4, 35 (1975).

29. S. Y. Li, F. M. Guo, Y. Song, A. M. Chen, Y. J. Yang, and
M. X. Jin, Phys. Rev. A 89, 023809 (2014).

30. S. Li and M. Jin, Chin. Opt. Lett. 13, 121901 (2015).

31. K. Lim, M. Durand, M. Baudelet, and M. Richardson, Sci. Rep. 4, 7217 (2014).

32. F. Théberge, W. Liu, P. T. Simard, A Becker, and S. L. Chin, Phys. Rev. E 74, 036406 (2006).

33. W. Demtröder, Molecular Physics: Theoretical Principles and Experimental Methods (Wiley-VCH Verlag GmbH\&Co., 2005). 